\title{
Partial Properties of Four Glycosidases in Normal Human Lens and Variations in Their Enzyme Activities during Aging and with the Advance of Lens Coloration
}

\author{
Akira KAMEI \\ Department of Biochemistry, Faculty of Pharmaceutical Sciences, Meijo University, 150 Yagotoyama, Tenpaku-ku, Nagoya, \\ Aichi 468-8503, Japan. Received March 16, 1998; accepted June 6, 1998
}

This paper reports the active glycosidases in normal human lenses and their partial properties. In addition, variations in their enzyme activities during aging and with the advance of lens coloration were also examined. Five glycosidases, $\alpha$-D-glucosidase, $\beta$-D-glucuronidase, $N$-acetyl- $\beta$-D-glucosaminidase, $\beta$-D-cellobiosidase, and $\alpha$ L-fucosidase, were detected as active glycosidases in the normal human lens. However, the activity of $\beta$-D-cellobiosidase was considerably low as compared to the other four glycosidases. Thus, this enzyme was omitted from this study. The four glycosidases, $\alpha$-D-glucosidase, $\beta$-D-glucuronidase, $N$-acetyl- $\beta$-D-glucosaminidase, and $\alpha$ L-fucosidase, showed that their enzyme activities fell abruptly between the ages of 40 and $\mathbf{5 0}$. Furthermore, the $K_{\mathrm{m}}$ values of their enzymes exhibited some variability during aging. Namely, the $K_{\mathrm{m}}$ values of their enzymes indicated the lowest value between the 40 age group and 50 age group, suggesting that the substrate affinity became the strongest at these age groups.

Then, variations in enzyme activity with the advance of lens coloration were examined. In each cases, the specific activity of detectable glycosidases in color lenses, white to brown, decreased. In particular, the specific activity of enzymes in the brown lens was very low, indicating that glycosidases in the brown lens may scarcely display their enzyme activities.

Key words normal human lens; glycosidase activity; lens coloration, aging

It is a well known fact that the senile cataract is the main cause of human blindness, and that the ultimate cause of the cataractogenesis results from the aggregation and insolubilization of lens proteins. ") Thus, many investigators have searched for the mechanism of lens protein insolubilization or the cause of senile cataract formation. However, the precise events of senile cataract formation are as yet unknown. Several studies suggest that the glycation of lens proteins with various sugars is suspected as a cause of aggregation and insolubilization of lens proteins. ${ }^{2)}$ A few studies have supported this inference. They have demonstrated that the proteins of senile cataractous lenses undergo glycation considerably more frequently compared with normal lenses. As sugars or their derivatives reacting with lens proteins, glucose, glucose-1-phosphate, glucose-6-phosphate and fructose have been reported at the present time. ${ }^{3)}$ However, nobody has proven the exact source of supply of such monosaccharides, though there are various polysaccharides, proteoglycans, glycogen and glycolipid in mammalian lenses.

Furthermore, recent studies reported that cataractous human lenses became white, yellow or brown in senile cataracts, and that glycation might be mainly suspected as the causes of this lens coloration. However, not much corroborating evidence has been found for glycation.

Concerning glycosidases in mammalian lenses, Dreyfus et $a l$. reported that there were several glycosidases in the lenses of bovine, rabbit and aged human. ${ }^{4}$ In addition, they reported an increase in the activities of several glycosidases in the lenses of senile cataract and diabetic cataract. Thus, some investigators have suggested that the monosaccharides reacting with lens proteins might arise from endogenous lens materials by enzymatic hydrolysis. However, to date no one knows the precise properties of the glycosidases in the human lens. I am convinced that it is very important to reveal the nature of glycosidases in normal and cataractous human lenses in order to find out the source of the monosaccharides participating in glycation.

The current paper describes the species of active glycosidases detected in the normal human lens, as well as their partial properties relating to optimal $\mathrm{pH}$, the optimal temperature, specific activity and substrate affinity $\left(K_{\mathrm{m}}\right.$ value). Furthermore, the variation in their enzyme activities during aging and with the advance of lens coloration, white to brown, is also described. The enzyme activity of the glycosidase was measured using 4-methylumbelliferyl-sugar derivatives as a substrate.

\section{MATERIALS AND METHODS}

Human Lens Used Normal human lenses were kindly donated by Dr. Horwitz, Jules Stein Eye Institute, University of California, Los Angeles. Normal human lenses were obtained from autopsy eyes that were removed 4 to $8 \mathrm{~h}$ following death. Upon removal, the eyes were stored at $-80^{\circ} \mathrm{C}$ until use. Senile cataractous lenses were also obtained during routine cataractous surgery at the same institute.

Materials 4-Methyumbelliferyl-sugar (4-MU-sugar) derivatives as substrates were purchased from Wako Pure Chemical Industries, Japan. Other chemicals were of analytical glade or of the highest purity available.

Preparation of Crude Glycosidase from Human Lens A human lens was homogenized in $1.5 \mathrm{ml}$ of $50 \mathrm{~mm}$ sodium phosphate buffer, $\mathrm{pH} 7.2$, in an ice bath and the homogenate was centrifuged at $25000 \times \boldsymbol{g}$ for $30 \mathrm{~min}$ at $4{ }^{\circ} \mathrm{C}$. The supernatant was used as the crude enzyme solution.

Detection of Active Glycosidase in Human Lens Glycosidase activity was assayed according to the method of Howkins et al., in which 4-MU-sugar derivatives were used for substrates. ${ }^{4 b)}$ Briefly, $50 \mu$ l of the substrate solution of each $1.0 \mathrm{~mm} 4-\mathrm{MU}$-sugar derivative and $200 \mu \mathrm{l}$ of $0.2 \mathrm{M}$

(C) 1998 Pharmaceutical Society of Japan 
sodium phosphate-0.1 $\mathrm{m}$ citric acid buffer, $\mathrm{pH} 7.0$, were mixed, and incubated for $5 \mathrm{~min}$ at $37^{\circ} \mathrm{C}$. Then, $50 \mu \mathrm{l}$ of enzyme solution was added, followed by incubation for $30 \mathrm{~min}$ at $37^{\circ} \mathrm{C}$. The reaction was terminated by adding $1 \mathrm{ml}$ of $0.2 \mathrm{M}$ glycine-sodium hydroxide buffer, $\mathrm{pH} 10.7$. The fluorescence at $E_{\mathrm{m}}=450 \mathrm{~nm}\left(E_{\mathrm{x}}=365 \mathrm{~nm}\right)$ of the liberated 4-MU was measured immediately using a Shimadzu RF-5000 Spectrophotometer. Free 4-MU was used as a standard.

Assay of Enzyme Activity The enzyme activity was assayed by the method of Hawkins et al., described above. ${ }^{4 b)}$ One unit of enzyme activity was defined as the amount which transformed $1.0 \mu \mathrm{mol}$ substrate $/ \mathrm{min}$ under optimal conditions. The specific activity was represented as $\mathrm{mU} / \mathrm{mg}$ protein.

The $K_{\mathrm{m}}(\mu \mathrm{M})$ value of the enzyme was measured as follows. Briefly, $50 \mu$ l of the substrate solution at various concentrations, 5.1, 10.2, 20.4, 40.8 and $81.6 \mu \mathrm{M}$ (final concentration), and $200 \mu \mathrm{l}$ buffer at the optimal pH for each enzyme, were mixed. The mixture was then pre-incubated for $5 \mathrm{~min}$ at respective optimal temperature, then $100 \mu \mathrm{l}$ of the enzyme solution was added to the mixture. Subsequently, the mixture was incubated for $30 \mathrm{~min}$ at the appropriate optimal temperature. After that, the reaction was terminated adding

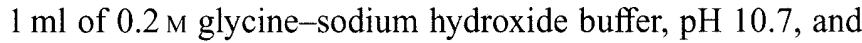
the liberated 4-MU was measured by a spectrophotometer as described above. The $K_{\mathrm{m}}$ values of glycosidases were determined by using double-reciprocal plots.

Determination of Optimal $\mathbf{p H}$ and Temperature The optimal $\mathrm{pH}$ of the enzyme was measured in $0.2 \mathrm{M}$ sodium phosphate- $0.1 \mathrm{M}$ citric acid buffer over a range of $\mathrm{pH}$ from 3.0 to 8.0 , and $0.1 \mathrm{M}$ potassium phosphate- $0.05 \mathrm{M}$ sodium borate buffer, $\mathrm{pH} 9.0$, following $30 \mathrm{~min}$ incubation at $37^{\circ} \mathrm{C}$.

The optimal temperature was also determined in the optimal $\mathrm{pH}$ buffer following 30 min-incubations at various temperatures.

Protein Assay Protein was measured by the method of Bradford. ${ }^{5)}$ Bovine serum albumin, $1.39 \mathrm{mg} / \mathrm{ml}$, was used as a standard.

\section{RESULTS}

Detection of Active Glycosidases in Human Lens First, the active glycosidases in human lenses of the 40 age group were examined using various 4-MU-sugar derivatives available commercially: that is, $4-\mathrm{MU}-\alpha$-D-glucoside (4-MU- $\alpha$-D-Glc), 4-MU- $\beta$-D-Glc, 4-MU- $\beta$-D-galactoside (4MU- $\beta$-D-Gal), 4-MU- $\alpha$-D-Gal, 4-MU- $\alpha$-D-glucuronide (4MU- $\alpha$-D-GlcUA), 4-MU- $\alpha$-D-mannoside (4-MU- $\alpha$-D-Man), 4-MU- $\alpha$-L-arabinoside (4-MU- $\alpha$-L-Ara), 4-MU- $\beta$-L-fucoside (4-MU- $\beta$-L-Fuc), 4-MU- $N$-acetyl- $\beta$-D-glucosaminide (4-MU$\beta$-D-GlcNAc), 4-MU- $\beta$-D-cellobioside (4MU- $\beta$-D-Cel), 4 MU- $\beta$-D-xylopyranoside (4-MU- $\beta$-D-Xyl), 4-MU- $\beta$-D-lactoside (4-MU- $\beta$-D-Lac), and 4-MU- $\alpha$-L-fucoside (4-MU- $\alpha$-LFuc). As a result, five glycosidases, $\alpha$-D-glucosidase, $\beta$ D-glucuronidase, $N$-acetyl- $\beta$-D-glucosaminidase, $\beta$-D-cellobiosidase and $\alpha$-L-fucosidase, were detected as active enzymes. Others were not detectable. Figure 1 shows the relative activity of glycosidases detected in the normal human lens. As shown in the figure, the activity of cellobiosidase was remarkably low as compared with other enzymes. Thus, the cellobiosidase was not investigated further in this experi-

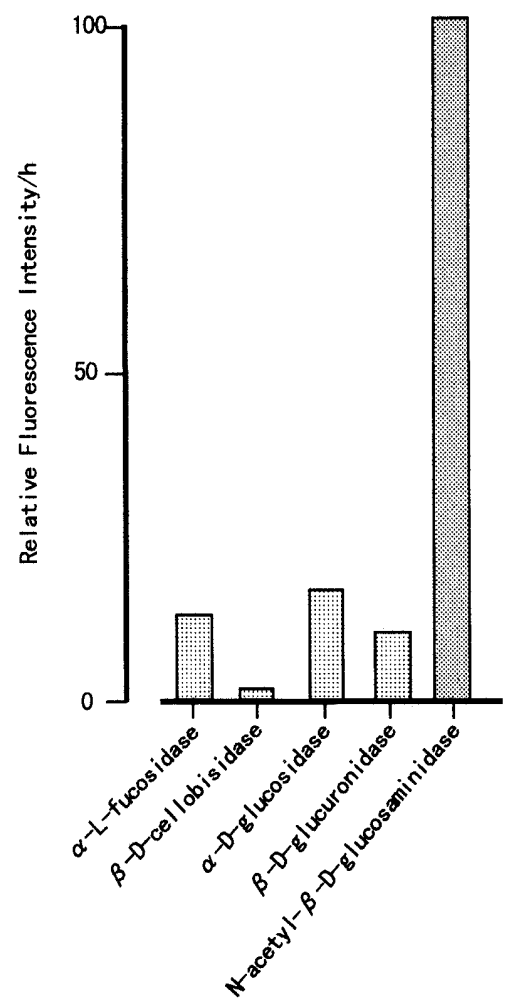

Fig. 1. Relative Enzyme Activity of Active glycosidases in Normal Human Lenses

This experiment was done using the normal human lens of the 40 age group and 13 different 4-MU-sugar derivatives. The detailed measurement of enzyme activity is described in "Materials and Methods". The experimental data represent the mean of two separate experiment with two different lenses of the same age.

ment.

Determination of Optimal pH and Optimal Temperature First, the optimal $\mathrm{pHs}$ of four glycosidases detected above were determined using 4-MU-sugar derivatives. Figure $2 \mathrm{~A}$ shows the optimal $\mathrm{pH}$ of four glycosidases. As a result, the optimal $\mathrm{pH}$ of $\alpha$-D-glucosidase, $\beta$-D-glucuronidase, $N$ acetyl- $\beta$-D-glucosaminidase, and $\alpha$-L-fucosidase were approximately $7.0,5.0,5.0$ and 6.0 , respectively.

The optimal temperatures were also determined under each optimal $\mathrm{pH}$, as shown in Fig. 2B. The optimal temperatures of $\alpha$-D-glucosidase, $\beta$-D-glucuronidase, $N$-acetyl- $\beta$-Dglucosaminidase and $\alpha$-L-fucosidase were approximately 40 , 60,40 , and $40^{\circ} \mathrm{C}$, respectively. Among them, the optimal temperature of $\beta$-D-glucuronidase was very high, higher than approximately $20^{\circ} \mathrm{C}$, compared with the other three enzymes.

Variation in Enzyme Activity during Aging The variation in the specific activity of four glycosidases, $\alpha$-D-glucosidase, $\beta$-D-glucuronidase, $N$-acetyl- $\beta$-D-glucosaminidase, and $\alpha$-L-fucosidase, were measured as a function of age, as shown in Fig. 3A. It was apparent that specific activities of the enzymes fell abruptly in the lenses of over the 50 -age group. In particular, the activities of four enzymes fell to one-tenth or less than in lenses of subjects under age 40 . In all cases, the enzyme activities fell dramatically with increasing age.

Then, the $K_{\mathrm{m}}$ values of four glycosidases were measured with respect to age. Four enzymes in the normal human lenses showed significant variations in their $K_{\mathrm{m}}$ values with aging. In lenses of the younger age group, subjects between 

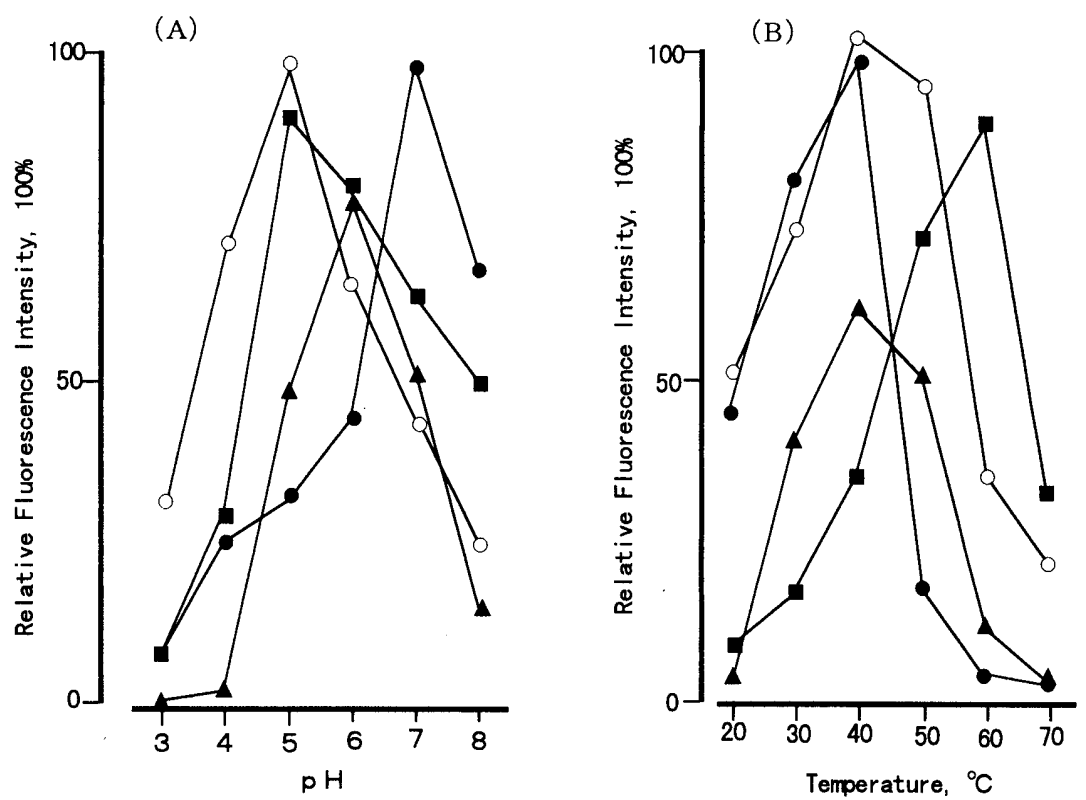

Fig. 2. Optimal $\mathrm{pH}$ and Optimal Temperature of Four Glycosidases, $\alpha$-D-Glucosidase, $\beta$-D-Glucuronidase, $N$-Acetyl- $\beta$-D-glucosaminidase and $\alpha$-L-Fucosidase

The detailed measurement of the optimal $\mathrm{pH}$ and optimal temperature is described in "Materials and Methods". The volume of enzyme solution for measuring $N$-acetyl- $\beta$-D-glucosaminidase activity was one-fourth those of the other three enzymes. The experimental data represent the mean of two separate experiments with two different lenses of the same age. $\alpha$-D-glucosidase; $\boldsymbol{\square}, \beta$-D-glucuronidase; $\boldsymbol{\Lambda}, \alpha$-L-fucosidase; $O, N$-acetyl- $\beta$-D-glucosaminidase.
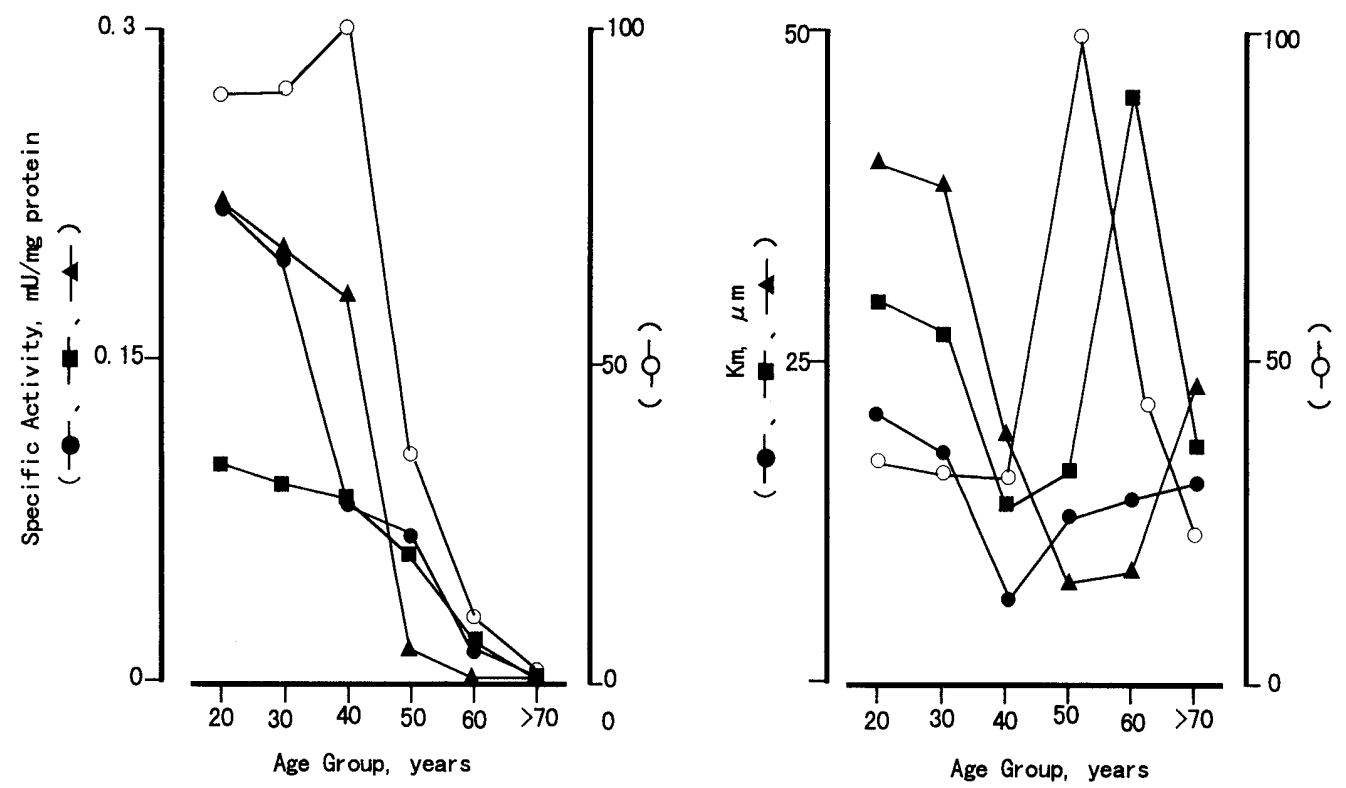

Fig. 3. Age-related Changes in Specific Activities and $K_{\mathrm{m}}$ Values of $\alpha$-D-Glucosidase, $\beta$-D-Glucuronidase, $N$-Acetyl- $\beta$-D-glucosaminidase and $\alpha$-L-Fucosidase Detected in the Normal Lens

Detailed experimental conditions are described in "Materials and Methods". The experimental data represent the mean of two separate experiments with two different lenses of same age. $\boldsymbol{\Theta}, \alpha$-D-glucosidase; $\boldsymbol{\square}, \beta$-D-glucuronidase; $\boldsymbol{\Lambda}, \alpha$-L-fucosidase; $\bigcirc, N$-acetyl- $\beta$-D-glucosaminidase,

the 20 and 40 age groups, the $K_{\mathrm{m}}$ values of respective glycosidases fell, shown in Fig. 3B. However, the $K_{\mathrm{m}}$ values of $\beta$-D-glucuronidase and $N$-acetyl- $\beta$-D-glucosaminidase increased again at the 60 age group and 50 age group, respectively. After that, these values decreased again. On the other hand, the $K_{\mathrm{m}}$ values of $\alpha$-D-glucosidase and $\alpha$-L-fucosidase increased in the lenses of the over-50 age group. This indicates that the $K_{\mathrm{m}}$ values of glycosidases in the normal human lenses change significantly between the 40 and 60 age groups, suggesting that the characteristics of glycosidases and their substrate affinities change with age. This result also suggests that the $K_{\mathrm{m}}$ values of their glycosidase, except for
$N$-acetyl- $\beta$-D-glucosaminidase, were smallest in the lens of the 40 age group, indicating that the substrate affinity of those three glycosidases was largest at the 40 age group.

Variation in Enzyme Activity with Lens Coloration Finally, specific activities of four glycosidases in the cataractous lenses of various coloration, white, yellow and brown (Fig. 4), were determined. The lenses of the 60 age group were used were in this experiment. In all cases, the specific activity of glycosidases decreased with the advance of coloration, indicating that the progression of lens coloration may inhibit glycosidase activity in the human lens, as shown in Fig. 5. In particular, the specific activity of the enzymes in 


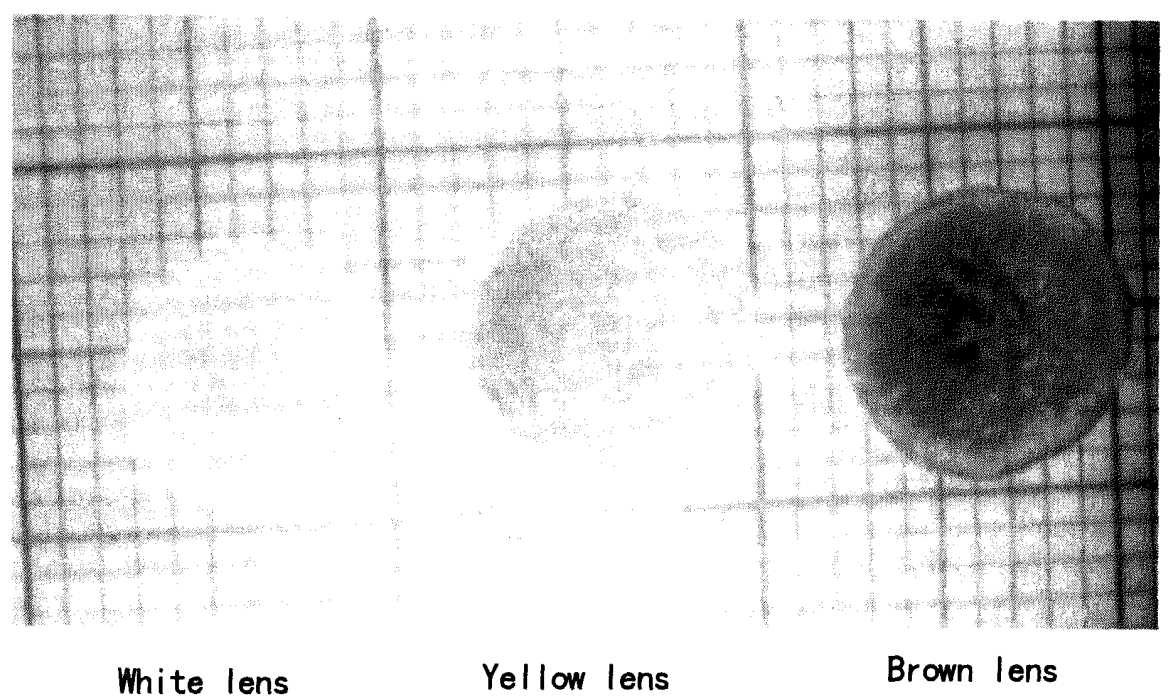

Fig. 4. Cataractous Lenses with Various Colors, White, Yellow and Brown
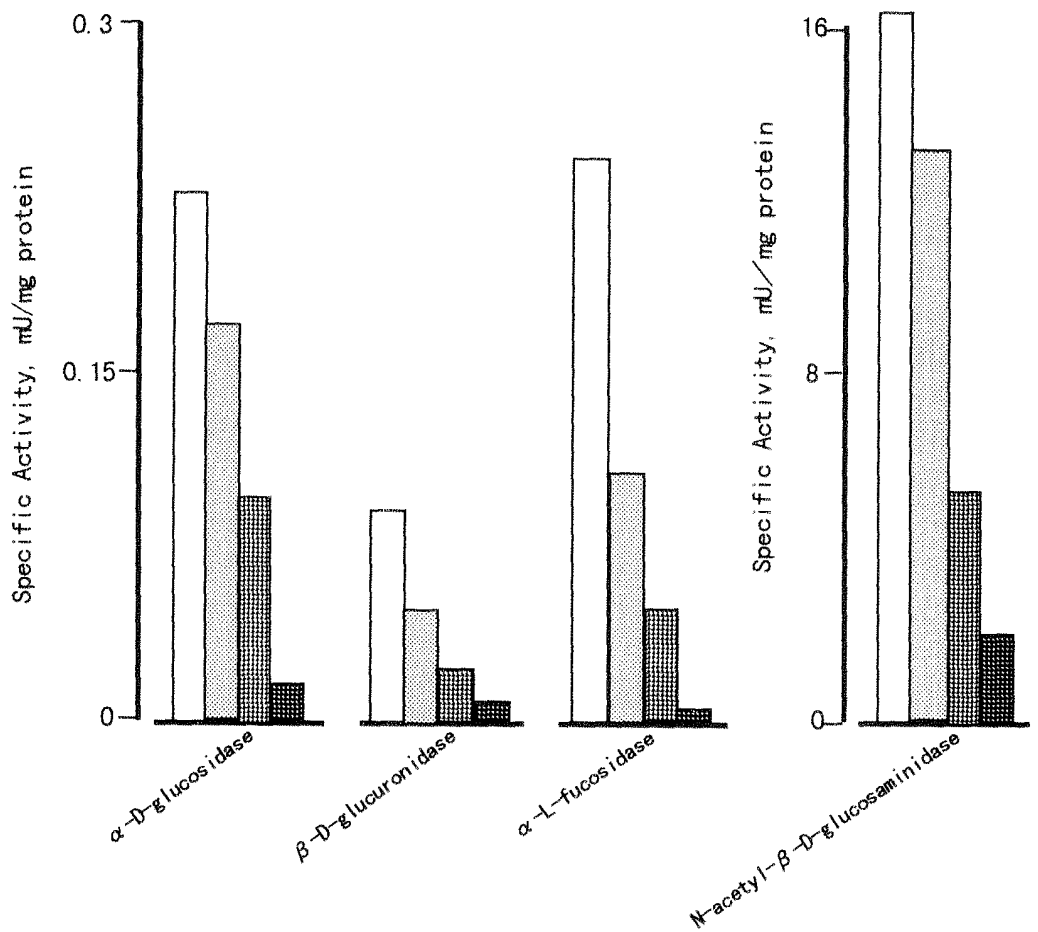

Fig. 5. Specific Activities of $\alpha$-I)-Glucosidase, $\beta$-D-Glucuronidase, $N$-Acetyl- $\beta$-I)-glucosaminidase, and $\alpha$-1-Fucosidase in the Normal with Transparency and Cataractous Lenses with Various Colors

$\square$, transparency of normal lenses; $\mathrm{B}$, white; yellow: lenses of the same age.

the brown lens was very low compared with that in the white and yellow lenses. This means that glycosidases in the brown lenses may scarcely display their enzyme activity.

\section{DISCUSSION}

The current study reports that in normal human lenses five glycosidases, $\alpha$-D-glucosidase, $\beta$-D-glucuronidase, $N$-acetyl$\beta$-D-glucosaminidase, $\alpha$-L-fucosidase and $\beta$-D-cellobiosidase are active. The specific activity of $N$-acetyl- $\beta$-D-glucosaminidase was remarkably higher than that of the other glycosidases. On the other hand, the enzyme activity of $\beta$-D-cellobiosidase was extremely low compared with other four enzymes. Dreyfus et al. reported nine kinds of glycosidases in the aged human lenses. ${ }^{4 d)}$ Furthermore, Carlin et al. reported six kinds of glycosidases in the cataractous lense. ${ }^{4()}$ I guess that this discrepancy might be attributable to the following: I used human lenses, which were removed 4 to $8 \mathrm{~h}$ following death. On the other hand, Dreyfus and Carlin used lenses from more than $24 \mathrm{~h}$ after death. Thus, lysosomal enzymes might be also detected in addition to cytoplasmic enzymes in their experiments.

The current study also reveals that the specific activity of four glycosidases in the normal lens becomes suddenly and extremely low in the lenses of the over 50 age group as compared with those of the lenses from the below 40 age group. In a previous paper, I reported a similar phenomenon regarding glutathione reductase in the human lens. The activity of 
this enzyme fell sharply in the lenses of the 50 age group. ${ }^{6)}$ Several investigators reported that various types of enzymes in the human lens reduce their enzyme activity as a function of age.

The current study also shows the complex variation in $K_{\mathrm{m}}$ values of four glycosidases during aging. The $K_{\mathrm{m}}$ values of their enzymes showed the lowest value at approximately the 40 age group, indicating that glycosidases in the normal lens have a higher substrate affinity than those of other age groups. Now, I have no idea how to explain this strange phenomenon.

Recent study suggests that lens coloration in aging may result from glycation, which may be a serious cause of senile cataract formation. ${ }^{7)}$ Thus, many investigators have attempted to clarify whether the monosaccharide responsible for the glycation of lens proteins comes from endogenous or exogenous lens material. The current study demonstrates that the glycosidase activity in the human lens decreases with the advance of lens coloration, white to brown. From these results, I presume that the monosaccharide may come from exogenous lens materials, because the glycosidase activity in the lens becomes very low with age and such a reduction in enzyme activity may render impossible the enzymatic release of the monosaccharide from endogenous lens materials.

Finally, I must mention that the data on the respective age groups is the mean of only two lenses, because it is very difficult to obtain several normal human lenses of an identified age. I realize that biochemical changes in human lenses are subject to a great deal of individual variation. Nevertheless, I believe that these data are useful for further research on the biochemistry of lenses and the mechanism of cataract formation.
Acknowledgment I thank Dr. Joseph Horwitz of the Jules Stein Eye Institute, University of California, Los Angeles, who provided several normal and cataractous lenses.

\section{REFERENCES}

1) a) Scalbert P., Birlouez-Aragon I., Exp. Eye Res., 56, 335-340 (1993); b) Swany M. S., Tsai C., Abraham A., Abraham E. C., ibid., 56, 177 - 185 (1993); c) Kamei A., Chem. Pharm. Bull., 40, 27892791 (1992); d) Oimomi M., Maeda Y., Hata F., Kitamura Y., Matumoto S., Baba S., Iga T., Exp. Eye Res., 46, 415-420 (1988).

2) a) Kamei A., Katoh N., Chem. Pharm. Bull., 39, 1272-1276(1991); b) Kamei A., Exp. Eye Res., 15, 235-244 (1991); c) Huby R., Marding J. J., Exp. Eye Res., 47, 53-59 (1988); d) Mayer T., Freedman Z. R., Clin. Chim. Acta, 127, 147-187 (1983).

3) a) Tomlinson, DR., Willars, GB., Culcutt NA., Curr. Eye Res., 8, 357-363 (1989); b) Furth A., Anal Biochem., 175, 347-360 (1989); c) Liang J. N., Chylack L. T., Invest. Ophthalmol. Vis. Sci., 28, 790794 (1987); d) Dische Z., Smirnow N., Zelmenis G., ibid., 1, 646$671(1971)$

4) a) Tashiro K., Iwamasa T., Kato H., Ogata S., Anai M., J. Biochem., 99, $693-701$ (1986); b) Hawkins L. A., Garg H. S., Awasthi Y. C., Srivastava S. K., Curr. Eye Res., 1, 497-50 (1982); c) Poenaru L., Skala H., Courtois Y., Dreyfus J. C., Exp. Eye Res., 25, $39-45$ (1977); d) Dreyfus J. C., Poenaru L., Skala H., ibid., 25, 47-51 (1977); e) Carlin R., Cotlier E., Invest. Ophthalmol. Vis. Sci., 10, $898-903$ (1971).

5) Bradford M., Anal. Biochem., 72, 248-254 (1976).

6) Kamei A., Biol. Pharm. Bull., 16, 870-875 (1993); Pau H., Graf P., Sies H., Exp. Eye Res., 50, 17-20 (1990).

7) a) Geller A. M., Kotb M. Y. S., Jerningan H. M., Kredich N. M., Exp. Eye Res,. 47, 197-204 (1988); b) Rathbum W. B., Bovis M. G., Curr. Eye Res., 5, 381-385 (1986); c) Rathbun W. B., Bovis M. G., Holleschau A. M., ibid., 5, 189-194 (1986); d) Dovrat A., Gershon D., Exp. Eye Res., 33, 651-661 (1981). 